\title{
Pelatihan Literasi Teknologi berbasis Ajaran Ki Hajar Dewantara untuk Mencegah Cyberbullying
}

\section{Astuti Wijayanti ${ }^{1}$, Laily Rochmawati Listiyani2* ${ }^{2 *}$ Flora Grace Putrianti ${ }^{3}$, Rini Nurhayati ${ }^{4}$, Nashiruddin Achmad ${ }^{5}$}

\author{
Universitas Sarjanawiyata Tamansiswa ${ }^{1,2,3,4,5}$ \\ astuti.wijayanti@ustjogja.ac.id, laily.listiyani@ustjogja.ac.id*,dgrace.p@ustjogja.ac.id rininut1@gmail.com \\ achmadnashiruddin10@gmail.com
}

\begin{abstract}
Very rapid technological developments can have positive and negative impacts on society. One negative effect that needs to be watched out is cyberbullying. This community service is carried out online targeting teenagers, educators and parents. This service aims to provide insight related to cyberbullying, parenting and the importance of technological literacy in assisting adolescent development so that it can prevent cyberbullying. The method of implementing this service is discussion, practice and question and answer. Online community service by way of Whatsapp lectures was attended by 95 people. The results of the dedication showed that the participants seemed enthusiastic in attending Whatsapp lectures with this theme. Cyberbullying and media literacy become new insights for participants. Curiosity towards the implementation of the teachings of Ki Hajar Dewantara is increasing. Parents and educators should be able to attend training regularly so that they can optimally assist and develop the potential of children, especially adolescents, so they avoid cyberbullying.
\end{abstract}

Keywords: literacy; technology; cyberbullying.

\begin{abstract}
Abstrak
Perkembangan teknologi yang sangat pesat dapat mengakibatkan dampak positif dan negatif bagi masyarakat. Salah satu dampak negatif yang perlu diwaspadai adalah cyberbullying. Pengabdian masyarakat ini dilaksanakan secara online dengan sasaran remaja, pendidik dan orang tua. Pengabdian ini bertujuan untuk memberikan wawasan terkait cyberbullying, pola asuh dan pentingnya literasi teknologi dalam mendampingi perkembangan remaja sehingga dapat mencegah terjadinya cyberbullying. Metode pelaksanaan pengabdian ini yaitu diskusi, praktik dan tanya jawab. Pengabdian masyarakat online dengan cara kuliah Whatsapp diikuti oleh 95 orang. Hasil pengabdian menunjukkan bahwa peserta nampak antusias dalam mengikuti kuliah Whatsapp dengan tema ini. Cyberbullying dan literasi media menjadi wawasan baru bagi peserta. Keingintahuan terhadap implementasi ajaran ki Hajar Dewantara semakin meningkat. Orang tua dan pendidik hendaknya dapat mengikuti pelatihan secara berkala sehingga dapat dengan optimal dalam mendampingi dan mengembangkan potensi anak terutama remaja sehingga terhindar dari cyberbullying.
\end{abstract}

Kata Kunci: Literasi; Teknologi; cyberbullying. 


\section{A. PENDAHULUAN}

Perkembangan era teknologi berlangsung sangat pesat. Perubahan tersebut menjadi dua sisi mata uang, dimana di salah satu sisinya dapat menumbuhkan harapan, namun di sisi lain dapat menimbulkan kekhawatiran timbulnya permasalahan baru di sekitar kita. Salah satu permasalahan yang marak saat ini yaitu cyberbullying pada remaja. Menurut Utami and Baiti (2018), tindakan cyberbullying dimudahkan dengan adanya akses media sosial. Seringkali, pelaku cyberbullying memposting tulisan kejam dan mengunggah foto orang lain/korban di sosial media dengan tujuan mengintimidasi dan merusak nama baik korban sehingga korban merasa tersakiti dan malu, sedangkan pelaku merasa puas dan senang karena tujuannya telah tercapai. Namun, kita tidak boleh pesimis dan antipati terhadap kehadiran teknologi tersebut, namun tetap optimis dan tetap berupaya untuk mengurangi kecemasan dari dampak yang akan ditimbulkan terutama pengaruhnya terhadap perilaku anak-anak jaman now.

Orang tua memiliki peranan yang sangat penting dalam pendidikan anak remaja di lingkungan keluarga. Setiap individu akan mengalami masa peralihan antara masa kanak-kanak dan masa dewasa yang mengandung perubahan besar fisik, kognitif dan psikososial yaitu masa remaja. Hall (Diananda, 2019) menambahkan bahwa masa remaja menjadi masa pergolakan yang penuh konflik dan buaian suasana hati dimana pikiran, perasaan, dan tindakan bergerak pada kisaran antara kegembiraan dan kesedihan, kebaikan dan godaan, serta kesombongan dan kerendahan hati. Pada masa ini, mereka memiliki ambisi yang tinggi, tidak realitis, dan pemikirannya terlalu muluk sehingga jika mendapat penilaian orang lain sensifitasnya akan sangat meninggi terutama bila dianggap sebagai anak kecil. Oleh karena itu, orang tua akan membutuhkan kematangan dalam berpikir, berpengalaman, keterampilan dan juga kematangan tingkat ekonomi untuk dapat membentuk pribadi dan perilaku anak yang matang (Jannah, 2015). Optimalisasi pendidikan keluarga diharapkan dapat mencegah dan meminimalisir terjadinya bullying terutama cyber bullying pada anak jaman now.

Tumbuh kembang anak di era modern sudah mengalami banyak perubahan, dikarenakan kebutuhan anak semakin meningkat dan terkadang tidak dapat dipenuhi di dalam keluarga. Namun demikian, orang tua dan anggota keluarga lainnya tidak dapat melepaskan diri dari tanggung jawabnya untuk mendidik anak-anaknya. Rahayu (2005) menjelaskan bahwa orang tua dalam kegiatan pengasuhan tidak hanya bagaimana memperlakukan anak, tetapi juga cara mendidik, mengarahkan, dan melindungi anak mereka sejak kecil hingga dewasa sesuai dengan nilai, norma dan kebudayaan masyarakat. Hal tersebut senada dengan pendapat $\mathrm{Ki}$ Hajar Dewantara tentang tripusat pendidikan yang menyebutkan salah satu pusat pendidikan yaitu pendidikan dalam keluarga menjadi miniatur terkecil dari masyarakat yang memiliki tanggung jawab dalam mendidik individu anak agar menjadi masyarakat yang bermoral (Kurniawan, 2015). Keluarga adalah tempat sebaikbaiknya untuk melakukan pendidikan orangseorang (pendidikan individual) maupun pendidikan sosial sehingga menjadi pribadi yang utuh. Hal tersebut akan dapat mengembangkan kecerdasan spiritual dan kecerdasan emosional anak. Selain itu, peran pendidik di sekolah juga sangat penting sebagai tripusat pendidikan guna mencegah cyberbullying pada peserta didik di sekolah. Oleh karena itu, pihak keluarga hendaknya 
dapat meningkatkan kerjasamanya dengan lingkungan di sekolah maupun di masyarakat.

Melalui kegiatan pengabdian ini peserta dapat ikut serta mengidentifikasi cyberbullying yang terjadi di sekitar mereka, mengkaji literasi digital yang diperlukan dalam pendampingan anak, dan mendiskusikan pemecahan masalah terkait dengan cyberbullying dan literasi digital. Melalui literasi digital pada orang tua dan pendidikan ini diharapkan dapat menjadi alternatif solusi agar orang tua dan pendidik dapat selalu tanggap dengan perubahan dan selalu inovatif dalam mendampingi remaja sehingga dapat menangkal terjadinya cyberbullying dan kejahatan cyber lainnya.

Ipteks/jasa yang ditawarkan untuk menyelesaikan persoalan mitra antara lain yaitu: 1) peningkatan SDM dengan memberikan pemahaman dan ketrampilan kepada masyarakat mitra mengenai pencegahan dan penanganan cyberbullying, mengelola emosi serta etika bermedia sosial dengan pelatihan, dan pembuatan produk tentang cyberbullying sehingga membentuk masyarakat yang peduli dengan cyberbullying, dapat mengatasi cyberbullying yang ada di lingkungannya; dan 2) peningkatan manajemen organisasi yaitu dengan pemberdayaan masyarakat mitra untuk mengatasi permasalahan cyberbullying yang muncul dengan pembentukan dan kepengurusan Whatsapp grup dan Komunitas Omah Peduli Cyberbullying

Jenis luaran yang dihasilkan yatu 1) Peserta memahami dan memiliki pengetahuan tentang cyber bullying, bahaya cyberbullying dan ajaran Ki Hadjar Dewantara untuk mencegah cyberbullying; 2) Peserta memahami dan memiliki pengetahuan tentang teknologi yang berkembang saat ini sehingga bisa mengontrol anak saat berselancar di internet; dan 3) Anggota grup memahami pentingnya berkomunikasi dengan ahli agar dapat menyelesaikan persoalan terkait cyberbullying. Anggota grup memiliki kepekaan terhadap gejala cyber bullying sehingga segera berkonsultasi dengan ahlinya.

\section{B. PELAKSANAAN DAN METODE}

Pengabdian masyarakat ini dilaksanakan bekerjasama dengan Persatuan Muda Mudi Wonokromo II Yogyakarta dan Ristekdikti. Kegiatan ini dilaksanakan pada tanggal 6 s.d 8 Juli 2020. Bersamaan dengan terjadinya pandemi covid-19, maka pengabdian masyarakat dilaksanakan dalam jaringan (daring) yaitu melalui kuliah Whatsapp pada grup "Omah Peduli Cyberbullying". Peserta kegiatan ini sejumlah 95 orang. Persiapan yang dilakukan oleh tim pengabdian yaitu; 1) koordinasi dengan padukuhan dan remaja Persatuan Muda Mudi Wonokromo II; 2) pembuatan publikasi dan materi kuliah Whatsapp, dan 3) pembuatan presensi dan lembar evaluasi. Kegiatan pengabdian masyarakat ini dilaksanakan dengan metode berdiskusi dan bertanya jawab. Tim pengabdian memberikan 1) sosialisasi terkait dengan ajaran Ki Hajar Dewantara, cyberbullying di era milenial dan literasi digital bagi orang tua, dan 2) diskusi tanya jawab terkait permasalahan pengabdian masyarakat. Pengumpulan data pada pengabdian ini dengan menggunakan lembar evaluasi dan dokumentasi yang akan dijabarkan secara deskriptif. Respon peserta terhadap kegiatan pengabdian ini dapat dilihat dari lembar evaluasi yang telah diisi oleh peserta pada akhir kegiatan.

\section{HASIL DAN PEMBAHASAN}

Kegiatan pengabdian masyarakat
dilaksanakan oleh tim pengabdian 
masyarakat UST dan remaja Persatuan Muda Mudi Wonokromo II Yogyakarta. Abdimas kuliah Whatsapp (Kulwap) pada grup "Omah Peduli Cyberbullying" ini berjalan dengan lancar. Peserta yang berpartisipasi dalam kegiatan tersebut sejumlah 95 orang dengan sebaran pada gambar 1 .

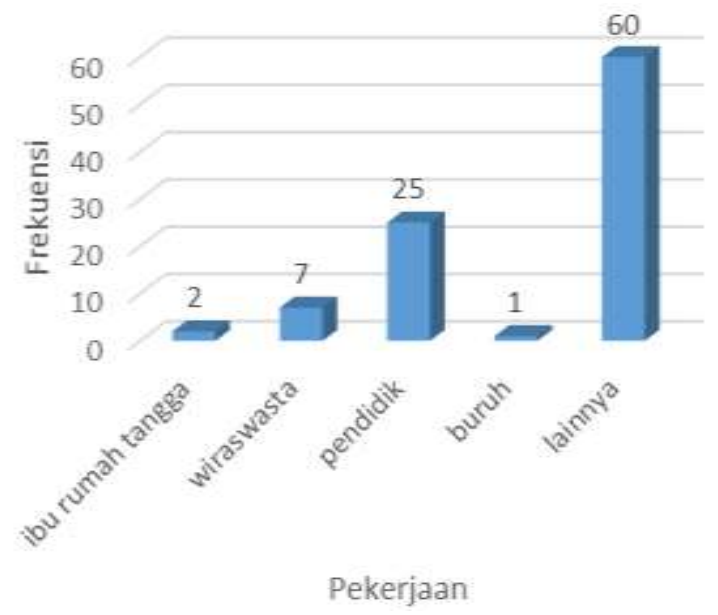

Gambar 1. Sebaran Pekerjaan Peserta Kulwap

Pembagian tugas tim pengabdian ditampilkan pada Tabel 1.

Tabel 1. Pembagian Tugas Tim Pengabdian

\begin{tabular}{rll}
\hline \multicolumn{1}{c}{ No } & \multicolumn{1}{c}{ Nama } & \multicolumn{1}{c}{ Tugas } \\
\hline \multicolumn{1}{c}{ 1 } & Astuti & Koordinator kegiatan \\
& Wijayanti, & dan narasumber \\
& M.Pd.Si & literasi digital \\
2 & Laily & Sekretaris kegiatan \\
& Rochmawati & dan narasumber \\
& Listiyani, M.Pd & cyberbulying \\
& Flora Grace & Admin grup dan \\
& Putrianti & moderator kulwap \\
4 Nashiruddin & Kesekretariatan dan \\
& Achmad & koordinator pemuda \\
5 Rini Nurhayati & Koordinator \\
& & Kesekretariatan \\
& & online \\
\hline
\end{tabular}

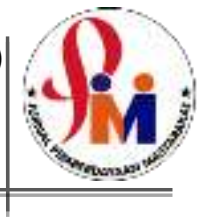

Kegiatan dari seorang Narasumber 1 dan Narasumber 2 serta beberapa pertanyaan dari peserta dalam diskusi Kulwap seperti pada Gambar 2 dan Gambar 3.
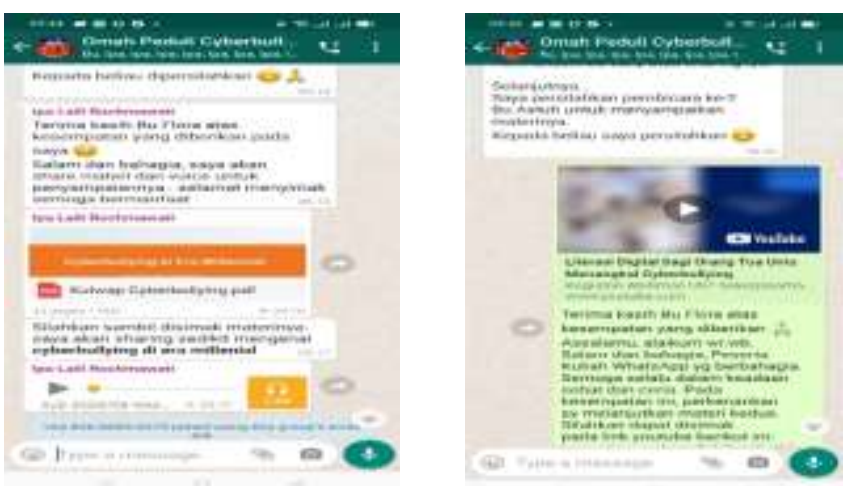

Gambar 2. Screenshot Narasumber 1 dan Narasumber 2
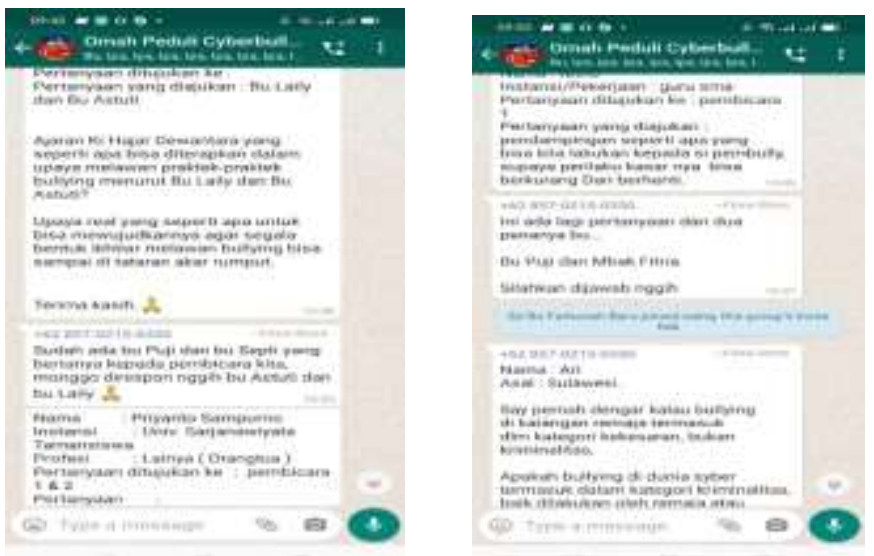

Gambar 3. Screenshot Beberapa Pertanyaan Peserta dalam Diskusi Kulwap

Habitus dan lingkungan mempunyai efek dalam penggunaan media sosial di kalangan remaja, serta didorong adanya modal atau alat untuk mengakses dunia maya (Utami, 2014). Lingkungan tersebut menjadi tempat remaja untuk mendapatkan pengakuan terutama di sosial media agar tidak dikatakan gaptek ataupun ketinggalan jaman. Habitus atau kebiasaan remaja ini terbentuk karena lamanya posisi siswa tersebut dalam kehidupan dunia maya. 
Winoto dan Sopian (2019) menambahkan bahwa remaja memiliki pandangan terkait perilaku cyberbullying di media sosial khususnya facebook dipengaruhi oleh interaktivitas diantara orang-orang yang terlibat berinteraksi dalam media tersebut, konektivitas dan juga kemudahan dalam mengakses informasi. Ketika remaja semakin mudah dalam mengakses akses informasi melalui media sosial, maka akan semakin mudah pula mereka dalam menyebarkan pesan cyberbullying pada orang lain. Hal tersebut mengakibatkan orangtua kesulitan dalam mengawasi aktivitas internet anak padahal mereka belum belum cukup matang untuk menyaring segala informasi, termasuk konten negatif di internet (Pinariya dan Lemona, 2019).

Fatmawati (2019) menambahkan bahwa pola asuh merupakan pola interaksi antara orang tua dengan anak dalam rangka pendidikannya agar anak dapat hidup selaras dengan lingkungannya. Anak-anak didik dengan berbagai macam pola asuh yang sesuai dengan kepribadian dan sikap orangtua mereka (Loretha, Nurhalim and Utsman, 2017). Orangtua dapat menjadi model (contoh) bagi remaja terkait nilai dan norma kehidupan yang mereka ajarkan, memberi ruang untuk berdialog dan bermusyawarah tentang berbagai permasalahan yang dihadapi remaja; serta menghargai pendapat remaja (Eka Putri and Noviekayati, 2015).

Generasi saat ini lebih pintar dari orang tuanya terutama dalam pemanfaatan teknologi digital, anak menyukai kebebasan dalam berselancar di dunia maya dan saat ini anak bebas terkoneksi dengan internet untuk membuat konten sendiri di berbagai sosial media yang mereka miliki. Pentingnya peran orangtua sebagai pendamping anak dalam menggunakan internet tidak lain karena anak belum mempunyai kecakapan teknis, pengetahuan maupun emosi dalam mengakses berbagai informasi dan hiburan melalui internet (Munawar, Fakhruddin, RC, \& Titi Prihatin, 2019). Orang tua dan pendidik tentunya dapat mengambil peran secara baik dengan pola pendekatan dan interaksi dengan anak dalam pengelolaan pendidikan.

Ki Hadjar Dewantara memiliki konsep belajar yang didasarkan pada sifat bawaan peserta didik yaitu, cipta, rasa, dan karsa yaitu metode among (Mujito, 2014), Metode ini memiliki arti menjaga, mendidik, dan membina berdasarkan kasih sayang. Lingkungan belajar harus saling terkait antara lembaga pendidikan di dalam keluarga, masyarakat, dan sekolah. Oleh karena itu, pembentukan lingkungan yang baik dapat dimulai dari sinergitas tiga pusat pendidikan sehingga anak dapat tumbuh dan berkembang baik dan dapat terbebas dari kejahatan digital.

Kemampuan digital diperlukan untuk memahami, menganalisis, menilai, mengatur dan mengevaluasi informasi dengan menggunakan teknologi digital. Menurut Lestari, dkk. (2018) Literasi digital yaitu kemampuan untuk membuat dan berbagi dalam perbedaan mode dan bentuk; untuk membuat, berkolaborasi dan berkomunikasi efektif dan untuk mengetahui bagaimana dan kapan menggunakan teknologi digital yang baik untuk mendukung proses ini. Kemampuan literasi digital inilah yang diperlukan oleh remaja, orang tua dan pendidik dalam menghadapi tantangan era milenial ini. Hal tersebut sesuai dengan 
pendapat Utami and Baiti (2018) bahwa untuk pencegahan cyberbullying pada remaja hendaknya dapat dilakukan dengan memberikan pelajaran tambahan mengenai pengenalan media, seperti literasi media dan mengajak beberapa pihak terkait dalam mengontrol hal yang dapat ditimbulkan dari dampak negatif penggunaan media sosial, serta bahaya cyberbullying.

Pada pengabdian ini, mengajak orang tua dan pendidik untuk dapat melakukan literasi digital, menyadari adanya cyberbullying di sekitar anak, dan komunikasi dengan anak atau remaja melalui pola asuh yang efektif. Cara tersebut yaitu dengan menjalin kelekatan, memberikan waktu rutun untuk berbicara berdua saja, menyampaikan bahwa anak boleh memiliki rahasia, namun bukan yang menyangkut hidup mati/masa depan dia, memperbaiki cara berbicara dengan lebih lembut dan mendidik, melakukan komunikasi berkualitas dengan memberikan keleluasaan namun juga batasan. Orang tua dan pendidik dapat memberitahu mana yang baik dan yang tidak, apa yang menjadi hobi dibebaskan, difasilitasi dan motivasi serta jika salah diingatkan.

Orang tua dan pendidik dapat berlatih dan belajar "Niteni" atau mengerti dan mengenali media sosial yang sering dikunjungi anak dan bagaimana kejahatan cyber mengincar saat anak berinteraksi di dunia maya. Kemudian, "nirokke" atau menirukan cara pemanfaatan yang bijak dari teknologi dan menirukan cara pencegahan digital untuk menjaga anak dari kejahatan cyberbullying. Orang tua dan pendidik pada akhirnya dapat "nambahi" atau menambahkan dan memiliki beberapa alternatif solusi sehingga dapat membantu dan mendampingi anak dalam menghindari cyberbullying. Cara tersebut yaitu dengan membantu anak memahami informasi apa yang seharusnya bersifat pribadi, meminta anak memikirkan sebelum mempost sesuatu di dunia maya, memberikan arahan pentingnya pengaturan privasi, orang tua dan guru dapat mengunjungi dan pelajari akun media sosial seperti yang dimiliki oleh anak. Bicaralah dengan anak bahwa boleh membahas minat dan hobi namun tidak boleh berbau konten pornografi dan intimidasi kepada orang lain.

Sebelum memberikan izin anak dalam menggunakan gawai, orang tua perlu mengenal beberapa aplikasi umum yang terdapat dalam gawai dengan mengkaji panduan orang tua di google Play. Orang tua juga dapat mengaktifkan restricted mode di Youtube dan mengaktifkan google safe search serta menggunakan aplikasi parental control sehingga dapat membantu memudahkan dalam melakukan pendampingan dan meminimalisir anak terpapar kejahatan cyber terutama cyberbullying.

Berdasarkan evaluasi kegiatan pengabdian ini diketahui bahwa beberapa orang peserta pernah mengalami cyberbullying dan telah familiar dengan beberapa sosial media. Selain itu juga dapat diketahui bahwa peserta telah 1) memahami dan memiliki pengetahuan tentang cyberbullying, bahaya cyberbullying dan ajaran $\mathrm{Ki}$ Hadjar Dewantara untuk mencegah cyberbullying, 2) memahami dan memiliki pengetahuan tentang perubahan teknologi terkini sehingga dapat lebih mudah mengontrol anak saat berselancar di internet dan 3) memahami pentingnya berkomunikasi dengan ahli dan juga anak agar dapat menyelesaikan persoalan terkait cyberbullying. 


\section{PENUTUP}

\section{Simpulan}

Pesatnya perkembangan teknologi saat ini menuntut orang tua dan pendidik untuk dapat lebih meningkatkan kemampuan literasi digital sehingga dapat lebih optimal dalam mendampingi remaja dan melindungi mereka dari incaran kejahatan digital seperti cyberbullying. Media sosial dapat menjauhkan yang dekat dan mendekatkan yang jauh. Kegiatan pengabdian ini berhasil mengajak orang tua dan pendidik untuk lebih peduli terhadap perkembangan anak terutama remaja dalam perkembangannya serta mampu mengajak untuk dapat melakukan literasi digital sehingga dapat membantu anak dalam menangkal cyberbullying.

\section{Saran}

Kesadaran literasi digital dan menangkal cyberbullying pada diri pendidik dan orang tua perlu ditumbuhkan secara berkelanjutan dengan bekerjasama dengan berbagai pihak melalui kegiatan pelatihan parenting, mengikuti komunitas peduli cyberbullying, dan mengupdate informasi digital dari media serta teknologi yang ada. Orang tua dan pendidik hendaknya dapat selalu terbuka dan tanggap terhadap perubahan teknologi sehingga dapat mengarahkan anak dalam memperoleh dampak baik dari perubahan tersebut.

\section{Ucapan Terima Kasih}

Ucapan terima kasih terutama ditujukan kepada Ristekdikti, Prodi Pendidikan IPA UST, Prodi Psikologi UST, LP3M, Persatuan Muda Mudi Wonokromo II dan Padukuhan Wonokromo yang telah memberikan bantuan dalam kegiatan pengabdian ini. Kami sampaikan terima kasih juga kepada Komunitas Ibu Peduli Bullying yang telah memberikan doorprize pada kegiatan ini serta kepada pihak-pihak yang membantu pelaksanaan pengabdian masyarakat ini.

\section{E. DAFTAR PUSTAKA}

Diananda, A. (2019). Psikologi remaja dan permasalahannya. Journal ISTIGHNA, 1(1), 116-133. https://doi.org/10.33853/istighna.v1i1.2 0

Fatmawati, N. I. (2019). Literasi digital, mendidik anak di era digital bagi orang tua milenial. MADANI: Jurnal Politik Dan Sosial Kemasyarakatan, 11(2), 119-138. https://doi.org/10.1017/CBO97811074 15324.004

Jannah, M. (2015). Pola pengasuhan orang tua dan moral remaja dalam islam. JURNAL EDUKASI: Jurnal Bimbingan Konseling, $\quad 1(1), \quad 63$. https://doi.org/10.22373/je.v1i1.318

Kurniawan, M. I. (2015). Tri pusat pendidikan sebagai sarana pendidikan karakter anak sekolah dasar. PEDAGOGIA: Jurnal Pendidikan, 4(1), 41. https://doi.org/10.21070/pedagogia.v4i 1.71

Lestari, S., Kurnianingsih, I., \& Wardiyono, W. (2018). Pengukuran kemampuan literasi digital orang tua menggunakan instant digital competence assessment (instant dca). Bibliotech: Jurnal Ilmu Perpustakaan Dan Informasi, 3(2), 91108.

https://doi.org/10.33476/bibliotech.v3i2 .598

Mujito, W. E. (2014). Konsep belajar menurut ki hadjar dewantara dan relevansinya dengan pendidikan agama 
islam. Pendidikan Agama Islam, XI(1).

Munawar, M., Fakhruddin, RC, A. R., \& Titi Prihatin. (2019). Keterlibatan orangtua dalam pendidikan literasi digital anak usia dini. In Seminar Nasional Pascasarjana 2019 ISSN: 2686-6404 (pp. 1-5).

Pinariya, J. M., \& Lemona, M. (2019). Literasi dan sosialisasi internet ramah anak. Jurnal Abdi Moestopo, 2(2), 5056.

Rahayu, I. T. (2005). Pola pengasuhan islami sebagai awal pendidikan kecerdasan emosional. Psikoislamika: Jurnal Psikologi Dan Psikologi Islam, 2(2).

https://doi.org/10.18860/psi.v0i0.339

Utami, A. S. F., \& Baiti, N. (2018). Pengaruh media sosial terhadap perilaku cyberbullying pada kalangan remaja. Cakrawala - Jurnal Humaniora, 18(2), 257-262. Retrieved from http://ejournal.bsi.ac.id/ejurnal/index.p hp/cakrawala/article/view/3680/2624

Winoto, Y., \& Sopian, A. R. (2019). Remaja dan pandangannya terhadap cyberbullying pada media facebook. Commed: Jurnal Komunikasi Dan Media, 3(2).

Yana Choria Utami. (2014). Cyberbulliying di kalangan remaja (studi tentang korban cyberbullying di kalangan remaja di surabaya). Universitas Airlangga, 3(3), 1-10. 